\title{
Wildlife Treatment as Environmental Education Representative in Burnett's Work “The Secret Garden (1911)"
}

\author{
Mukarramah, Fathu Rahman, M. Amir P. \\ Faculty of Cultural Sciences, Hasanuddin University, Makassar, Indonesia.
}

\begin{abstract}
This study aims to elaborate on the environmental education reflected in the novel The Secret Garden by Frances Hodgson Burnett. Thisresearch uses qualitative methods and applies the perspective of environmental education to construct positive values of the close relationships between children and animals. The data derived from the novel itself were to determine environmental education, which contains ethical values towards the environment. This research indicates that educational values performed in this novel provide positive action and behavior of the characters, such as protecting and feeding animals. In addition, allof these activities are positive activities that are able to educate readers about having environmental behavior.
\end{abstract}

Keywords: Environmental Education, The Secret Garden, Frances Hodgson Burnett,Wildlife Treatment

\section{INTRODUCTION}

$\mathrm{T}$ he close relationship between humans and animals has long been an exciting topic. According to the study of Braje[1], the relationship between humans and other animals can be traced back to prehistoric times more than 50,000 years ago.Kato's creation story mentions that when God went out to create the world, he took his dog [2]. Gaita perceives the relationship between animals and humans through philosophy and historical perspective concerning this statement. Therefore, animals can be analogized as an inseparable part of human life.

Moreover, animals are always considered human's best friends, which can be perceived from the number of animals kept as pets by society, such as dogs, cats, birds, etc. A pet can also be a special friend, providing a means of escaping the world, getting rid of annoying reality, and avoiding destructive negative thoughts[3][4]. Like Beck and Brickel, Carver[5]states that millions of people worldwide love their pets, enjoying their companionship, going for walks, playing, and even talking to them.

Based on these assumptions, it has been known that the psychological state of people leads them to live with animals. People tend to have emotional intercourse with animals as well as human attachments to other creatures. It's just like other relationships between people and religious figures (such as God), the relationship between people and pets are also very different in intimacy, warmth, commitment, emotional participation, conflict, and other characteristics [6]. Realizing this fact, it is not improbable that there is an increasing awareness of the significant role of animals in human life.

Therefore, the writers believe that the attachment between people and animals is a positive connection that enables people to treat animals appropriately. However, few people take the opposite treatment. They treat animals arbitrarily and use them for personal gain. Today, animal cruelty has become an important issue facing society. Therefore, the problem of human abuse of animals has become a trend of discussion worldwide. Animal cruelty cases make headlines worldwide every day, whether it is people who kill neighbour's cats, sick people and hoarders of dying animals, who will freeze to death in the middle of winter, and hungry dogs tied to families outside [7].

In this case, human violence against animals can also be seen in the way people destroy the natural environment, such as deforestation, because it is assumed that a forest is a comfortable place for most animals. In addition, the cruelty to animals is also evidenced by a large number of items of clothing made of animal leather. From an Australian perspective, Krien[8] states that animals in 2011 were a big year. Further, she says that there is an obvious proliferation of animal print clothing on the streets, and media campaigns on controversial animal issues have increased significantly. In this regard, the existence of animals as an important species in human life has awakened several circles to promoting protests regarding this matter, including children.

According to Bone[9],2011 was a year that many children participated in protests against human cruelty to animals. Besides, she pointed out that the images of these protests may arouse fierce debate and cause tremendous emotional turmoil. Here, the existence of protests is a justification for the existence of animals committed by certain groups aware of the important role of animals in human life. Therefore, the author believes that protest is a persuasive behavior, inviting people to love animals properly. In this case, persuasive action can be achieved not only through actions taken directly on the street but also through the language skills contained in literary works. This is because literary works usually contain good values, which are implicitly conveyed through their constituent elements. According to Rahman [10], a good literary works should always contain values that are implicitly 
or explicitly included in the structure of literary works. These are implicitly present in plots, settings, characters and themes, or in arrays, couplets, rhythms and rhythms. Therefore, as a literary work, children's books contain lofty information and value and can be used as an effective way to provide teaching and education to readers. Regev [11] believes that children's literature has always been regarded as one of the clear means to educate and train children. Therefore, it turns out that literature plays a vital role in changing readers' views on certain things (including animal issues). In addition, there is a children's book called The Secret Garden, which describes the close relationship between children and animals. It is considered an attractive book and the object of literary research related to environmental education.

The question is that, how is the study of environmental education values portrayed in the novel, The Secret Garden by Frances Hodgson Burnett?

\section{LITERATUREREVIEW}

\section{A. Empathy for Animals as Educational Representative}

The behavior of humans interacting with various creatures shows the emotional bond between humans and animals. Therefore, many people often feel sad after losing their pet stars. The attachment between humans and animals is usually so strong that people's mourning at a funeral is very similar to the feelings and behavior of losing a family member. In this case, the presence of animals close to human life causes children to participate in the interaction with animals. Therefore, Tipper [12] conducted a study on how children view animals in their lives. His research is aimed at people from 7 to 12 years old. As many as 49 children interviewed said that there is a close emotional connection between humans and animals. In addition, it was pointed out that children can easily express their love for animals and talk about them as individuals, friends and relatives. Not only were the children not ashamed of these connections, but they also had detailed conversations with animals and often turned the focus of the interview discussion to animal Tipper [12]. The relationship between animals and children is the emotional connection of empathy in the individual's psychology. Human beings as a society need enough empathy to interact correctly with the surrounding environment. In this context, empathy is usually defined as the ability to understand the feelings of others. Besides, empathy can be considered a stimulating emotional state that depends on the ability to perceive, understand, and care about the experiences or opinions of others or animals [13]. Therefore, empathy is a positive emotion that makes people always have good moral integrity towards other creatures (such as animals). Kasperbauer[14] pointed out that compassion is essential to moral concern. In addition, she added that empathy is the main psychological problem that animals can express through attitudes and actions, such as providing food and water to cats. Based on this explanation, the author believes that empathy can motivate humans to make environmental behaviors through good ethics and a broad view of the surrounding environment. In this case, it is necessary to have empathy to be able to apply good behavior patterns to the environment, which can educate or guide the younger generation to always love the environment by treating animals well.

\section{B. Environmental Education}

The behavior of humans interacting with various creatures shows the emotional bond betweenMartin Luther King of Kuko (2015: 8) believes that the function of education is to teach someone to focus and think critically. Therefore, the building of intelligence and character is regarded as the true purpose of education. Under such circumstances, children who are the heirs of life need to understand the importance of the environment as a place where human beings depend. The environment and biological existence should be properly preserved. Moreover, this can be achieved through environmental education. As Latief et al. stated that culture is the main term that encompasses the social behavior[15]. In this case, environmental education can be understood as a process of understanding values and clarifying concepts to develop skills and increase the necessary tools to understand and appreciate people, his culture, his natural biophysical environment, and the relationship between and people, Interrelationships [16]. Therefore, it can be assumed that environmental education aims to teach people the conditions for understanding surrounding phenomena. Therefore, it can be used as a medium to overcome various environmental problems facing people today.

This is consistent with the views expressed by Porter [17] and Palmer[18] that environmental education can be used as an essential tool for solving environmental problems that are dedicated to environmental protection. The purpose of environmental education is to influence the individual's inner appearance and understanding of the world and encourage people to carry out appropriate real-life behaviors internally [19]. However, the primary purpose of environmental education is to change the individual's perception of the environment. In this case, animals as part of the environment require special attention from humans. Also, in environmental education programs, good treatment of humans is one of the important things for animals to do.

\section{Environmental Knowledge}

Understanding the environment is essential to help people easily identify various environmental problems in their lives. This knowledge aims to examine the relationship between living things and the environment, so humans are considered obliged to protect the surrounding environment from obtaining a good quality of life. Nowadays, it is well known that human behavior will have an adverse effect on the earth's environment. Thus it is necessary to understand ecological behavior[20]. Regarding this statement, the writer believes that humans must own environmental knowledge because there are many problems related to the environment. According to Flick et al.[21] Environmental knowledge is 
important for generating ecological behavior, because individuals must know what type of action to take. Therefore, environmental knowledge is the intellectual premise of environmental behavior. In environmental education programs, it is necessary to develop a good relationship with animals or moral concepts. People who are exceptionally knowledgeable about the environment, especially children, will certainly show good treatment of animals. Knowledge of animals may affect children's beliefs and behaviors towards them, so establishing a positive attitude towards animals is one of the main goals of environmental education programs[22].

\section{Connectedness to Nature}

As an important learning program, environmental education guides people to always interact with nature. This interaction aims to establish a positive intimacy with nature so that humans can understand various natural phenomena that require special attention. Brigger et al.[23] the connection with nature refers to the close connection between the individual and nature. Considering that the close connection between humans and the natural environment is believed to encourage ecological behavior, it is considered necessary for humans to have good morals and moral consciousness. Deal with the surrounding environment, including animals. This is consistent with Steg and Vlek[24] view that the strength of the relationship between humans and nature is essential to promote ecological behavior because it trumps all other variables (for example, ethics and normative concerns). The connection between humans and the natural environment is an important requirement because this connection is the main requirement for creating ecological behavior. According to the research of Frantz and Mayeur[25], the relationship between man and nature is an important condition for shaping ecological behavior.

\section{RESEARCH METHOD}

This study is a qualitative research using libraries as a source of data. There are two kinds of libraries: personal library and institutional library. It also used online materials such as journals or non-printed material. The Data were analyzed by using descriptive analysis.

\section{RESULTS AND DISCUSSIONS}

The Secret Garden novel is a book for children written by Frances Hodgson Burnett in 1911. The novel is about children who like to interact with animals. The character of a child named Dickon is the main character. He is a very outstanding person who explains the close relationship between animals and children. However, the event is said to contain news and noble value. Therefore, the author believes that the lofty value of novels related to environmental education can be used as an effective means to educate people or readers. Nature is the place where activities are carried out, and the way children treat animals well is also an important value of environmental education issues reflected in the story. When Dickon approaches to nature by protecting and playing with animals, he can clearly illustrate the favourable reflections of these events. In this case, it depicts various animals living in harmony in a field called Moor. Dickon is a kid and often spends time in this place, hanging out with ponies, foxes, rabbits, birds, and even chickens. Therefore, his hobby of playing in nature and playing with various animals shows that he has good morals for the environment. This can be seen in the following quote:

Our Dickon, he's twelve years old and he's got a young pony he calls his own." "Where did he get it?" asked Mary. "He found it on th' moor with its mother when it was a little one an' he began to make friends with it an' give it bits o' bread an' pluck young grass for it. And it got to like him so it follows him about an' it lets him get on its back. Dickon's a kind lad an' animals likes him (Burnett, 1911:30)

Empathy is usually defined as the ability of humans to understand the situation of others around them. The above quote expresses Deakin's compassion and concern for life. His pleasure in playing in nature and treating animals well proves this. It can be assumed that feeding food to the pony is an application of empathy, so the author points out that empathy leads to the character's protection and love of animals. The pony needs food and invites him to feed the animal by feeding it bread slices and then pulling grass. Therefore, it can be assumed that the character uses empathy as a fundamental need to treat the environment well. His relationship with nature and his treatment of animals are considered to be an application of empathy, bringing readers aristocratic values. In addition, the following quotation clearly illustrates Dick's compassion for animals:

"Everybody knows him. Dickon's wanderin' about everywhere. Th' very blackberries an' heather-bells knows him. I warrant th' foxes shows him where their cubs lies an' th' skylarks doesn't hide their nests from him." (Burnett, 1911:39)

The paragraph contains two justification. First, Dickon is a sociable child who is often interacting with people in society. Second, he is a friendly child who closes to animals. In this case, the writer found that Dickon has a good ethic towards environment approving by the ability to treat all living things around properly. Here, a friendly character towards the society he applied to other creatures such as animals. His ability to locate the nest of foxes living in Moor indicates special attention and love to nature and animals. His life runs in harmony within in application of good ethics towards the surroundings by taking notice of the animals. Hence, all the activities depicted in the story are an important indicator of the noble values of environmental education. In this study, the noble values presented directly by the author imply that literary work can teach and educate readers through the intrinsic components of a novel. Below is another quote showing the concern for animals by protecting them lovingly;

He goes out just th' same as if th' sun was shinin'. He says he sees things on rainy days as doesn't show when it's fair 
weather. He once found a little fox cub half drowned in its hole and he brought it home in th' bosom of his shirt to keep it warm (Burnett, 1911:47)

Empathy in the quotation above is shown by the willingness to protect a fox cub he gets in the Moors implies visceral attention. He hugs the little fox to keep him warm then take the animal home to protect it. In this case, all the actions described in the quote are positive action showing good ethics towards the environment. This certainly contains decent value perceived as the reflection of educational tool related to environmental education. How the character treats animals well means command and moral messages that humans must love animals by protecting them suitably.

Moreover, Dickon interpreted as being close to other animals such as squirrels, cock pheasant, and rabbits. He often plays in natural surroundings encouraging people to know him as anenergetic child playing with various animals. It is clearly portrayed when he chose a tree to lean on while playing the flute as he played on the Moor field.

Further, the animals around him slowly drew near, and some of them were peeking through the bushes [26]. Here, the writer believes that Dickon properly adores nature by playing in nature without disturbing the animals living around him. As shown by the quotation above, playing the flute by pleasure is a positive representation proving that Dickon has noble ethics towards the environment.

"I think I do, and they think I do," he said. "I've lived on th' moor with 'em so long. I've watched 'em break shell an' come out an' fledge an' learn to fly an' begin to sing, till I think I'm one of 'em. Sometimes I think p'raps I'm a bird, or a fox, or a rabbit, or a squirrel, or even a beetle, an' I don't know it." (Burnett,1911: 86).

The paragraph above contains a basic sign that animals living in nature provide more knowledge for the character. How these animals live in nature is a meaningful object and becomes an interesting lesson. This activity means that Dickon is a character with a good attitude towards nature and animals. In addition, the positive interaction with these animals even made him feel like part of an animal species. Therefore, it can be assumed that this positive feeling results from caring for animals through good environmental behavior. Below, another quote describes Deakin, who is close to animals:

Dickon looked more puzzled than ever and even rubbed his hand over his rough head again, but he answered quite goodhumoredly. "I'm keepin' secrets all th' time," he said. "If I couldn't keep secrets from th' other lads, secrets about foxes' cubs, an' birds' nests, an' wild things' holes, there'd be naught safe on th' moor. Aye, I can keep secrets." (Burnett,1911: 87).

The closeness relationship between Dickon and the animals is implied by the paragraph above. How he lives near the animals in the Moors is indicated by the statement that he is able to keep the secrets of the animals that live there. He knows all about eggs and nests,"Mary went on. And he knows where foxes and badgers and otters live. He keeps them secret so that other boys won't find their holes and frighten them. He knows about everything that grows or lives on the moor." (Burnett, 1911: 126). In this case, the message and noble value of the novel are explained implicitly and clearly. How a child makes contact with nature and treats animals well is a moral message that is considered an important sign of educational value. The involvement of animals in activities carried out by Dickon contains noble values that educate readers, especially children. In this case, animals require protection and well treatment from humans like what is depicted in the novel The Secret Garden. A child is portrayed as a figure who has great empathy, which is realized through good ethics and positive actions towards the environment. Besides, the activities of a child who likes to play in nature and close to animals is a representation of a positive lesson providing essential values for readers. Thus, children who are suggested as the main readers of the novel can acquire a good understanding of things related to environmental behavior.

\section{CONCLUSION}

The Secret Garden novel contains noble values that can be studied from an environmental perspective. In this case, the lofty value of the novel can be tested by the active activities of being close to nature and properly protecting animals. In addition, literary research through environmental perspectives can help improve children's attitudes towards the environment and love for the environment. From the perspective of environmental education, literary researchers can know that literary works such as children's books provide a voice and insights into the environment. In addition, this research also reveals that the feature of the novel "Secret Garden" is that children show positive actions and behaviors, depicting noble information and values that can educate children to love animals. These positive contents are expressed in the form of being close to nature and being kind to animals.

\section{REFERENCES}

[1] T. J. Braje, "The Human-Animal Experience in Deep Historical Perspective," Psychol. Human-Animal Bond, pp. 63-80, 2011, doi: 10.1007/978-1-4419-9761-6_4.

[2] Raimond Gaita, The Philosopher's Dog. Melbourne: Text Publishing, 2016.

[3] A. M. Beck, "Companion animals and their companions: Sharing a strategy for survival," Bull. Sci. Technol. Soc., vol. 19, no. 4, pp. 281-285, 1999, doi: $10.1177 / 027046769901900404$.

[4] C. M. Brickel, "Initiation and Maintenance of the HumanAnimal Bond: Familial Roles from a Learning Perspective," Pets Fam., pp. 31-48, 2018, doi: 10.4324/9781315784656-4.

[5] L. F. Carver, "When pets are family, the benefits extend into society," Cover., pp. 1-4, 2019.

[6] S. Zilcha-Mano, M. Mikulincer, and P. R. Shaver, "An attachment perspective on human-pet relationships: Conceptualization and assessment of pet attachment orientations," J. Res. Pers., vol. 45, no. 4, pp. 345-357, 2011, doi: 10.1016/j.jrp.2011.04.001.

[7] A. N. Nwankwo, "Animal Cruelty: A Review Animal Cruelty: A Review," no. January 2013, 2014.

[8] Anna Krien, "Us \& Them: On the Importance of Animals," Q. 
Essay, 2011, [Online]. Available: http://www.quarterlyessay.com/issue/us-them-importanceanimals.

[9] J. Bone, "The animal as fourth educator: A literature review of animals and young children in pedagogical relationships," Aust. J. Early Child., vol. 38, no. 2, pp. 57-64, 2013, doi: $10.1177 / 183693911303800208$.

[10] F. Rahman, "The Revival of Local Fairy Tales for Children Education," Theory Pract. Lang. Stud., vol. 7, no. 5, p. 336, 2017, doi: $10.17507 /$ tpls.0705.02.

[11] M. Regev, "Reflections, Society, Ideology and Values in Israeli Children's Literature," 1992.

[12] B. Tipper, "A dog who i know quite well: : Everyday relationship between children and animals," Child. Geogr., vol. 9, no. 2, pp. 309-317, 2011.

[13] Seattle Aquarium, Best Practices in Developing Empathy toward Wildlife. 2015.

[14] T. J. Kasperbauer, "Rejecting Empathy for Animal Ethics," Ethical Theory Moral Pract., vol. 18, no. 4, pp. 817-833, 2015, doi: 10.1007/s10677-014-9557-1.

[15] M. R. A. Latief, N. J. Saleh, and A. Pammu, "The effectiveness of machine translation to improve the system of translating language on cultural context," IOP Conf. Ser. Earth Environ. Sci., vol. 575, no. $1, \quad 2020$, doi: 10.1088/17551315/575/1/012178.

[16] S. Sarmah, "Analysis of Environmental Education Components in the Existing Textbooks from Class V to VII," Dev. Adopt. By State Counc. Educ. Res. Train., vol. 6959, no. 271, pp. 271277, 2015.

[17] G. Potter, Environmental education for the 21st century: Where do we go now?, vol. 41, no. 1. 2009.

[18] J. Palmer, Environmental Education in the 21st Century:
Theory, Practice, Progress and Promise. London: Routledge, 1998.

[19] D. C. McClelland, "Testing for competence rather than for 'intelligence'.," Am. Psychol., vol. 28, no. 1, pp. 1-14, 1973, doi: $10.1037 / \mathrm{h} 0034092$.

[20] The Core Writing Team IPCC, "Climate Change 2014: Synthesis Report. Contribution of Working Groups I, II and III to the Fifth Assessment Report of the Intergovernmental Panel on Climate Change," Geneva, 2015.

[21] F. Jacqueline, G. K. Florian, and W. Mark, "Environmental knowledge and conservation behavior: exploring prevalence and structure in a representative sample," Pers. Individ. Dif., vol. 37, no. 8, pp. 1597-1613, 2004.

[22] P. Prokop and S. D. Tunnicliffe, “'Disgusting' animals: Primary school children's attitudes and myths of bats and spiders," Eurasia J. Math. Sci. Technol. Educ., vol. 4, no. 2, pp. 87-97, 2008, doi: 10.12973/ejmste/75309.

[23] A. Brügger, F. G. Kaiser, and N. Roczen, "One for all?: Connectedness to nature, inclusion of nature, environmental identity, and implicit association with nature," Eur. Psychol., vol. 16, no. 4, pp. 324-333, 2011, doi: 10.1027/10169040/a000032.

[24] L. Steg and C. Vlek, "Encouraging pro-environmental behavior: An integrative review and research agenda," J. Environ. Psychol., vol. 29, no. 3, pp. 309-317, 2009, doi: 10.1016/j.jenvp.2008.10.004.

[25] C. M. P. Frantz and F. S. Mayer, "The importance of connection to nature in assessing environmental education programs," Stud. Educ. Eval., vol. 41, pp. 85-89, 2014, doi: 10.1016/j.stueduc.2013.10.001.

[26] F. H. Burnett, The Secret Garden. New York: Grosset \& Dunlap, 1911. 